\title{
Avaliação da Capacidade de uso da terra na baCia hidrográfica do Ribeirão SÃo Lourenço - ITUiUtABa/MG
}

\author{
Lisiane da Silva Mendes ${ }^{1 *}$, Roberto Rosa²
}

1 Programa de Pós-Graduação em Meio Ambiente e Qualidade Ambiental - UFU, Uberlândia-MG, Brasil. Av. João Naves de Ávila, n 2121 - Bairro Santa Mônica - Uberlândia - MG - CEP 38400-902.

2 Docente do curso de Geografia da Universidade Federal de Uberlândia, Uberlândia-MG, Brasil. Av. João Naves de Ávila, nº 2121 - Bairro Santa Mônica - Uberlândia - MG - CEP 38400-902.

*Autor para correspondência: lisiane-sm@hotmail.com

Recebido em 20 de maio de 2019. Aceito em 21 de julho de 2019. Publicado em 31 de julho de 2019.

Resumo - A degradação do solo pode ser evitada a partir de estudos que indiquem o potencial de uso da terra. O objetivo deste trabalho foi avaliar a capacidade de uso das terras e reconhecer as áreas prioritárias para preservação na bacia hidrográfica do Ribeirão São Lourenço, em Ituiutaba/MG. Por meio de técnicas de geoprocessamento, os dados foram compilados para classificação das terras no sistema de capacidade de uso. Em torno de $88,82 \%$ da área da bacia está apta à agricultura (classes II e III). Na classe IV o uso agrícola é mais restrito, sendo indicado o cultivo perene. As áreas inaptas à agricultura (classes VII e VIII) possuem potencial prioritário para preservação, devido às condições do solo e declividade. A classificação das terras fornece subsídios importantes nos processos de planejamento ambiental, indicando os usos dentro do seu potencial evitando a sub ou sobreutilização da terra.

Palavras-chave: Sistema de Informação Geográfica, aptidão agrícola, capacidade de uso da terra, planejamento ambiental.

Evaluación de la capacidad del uso de la tierra en la cuenca hidrográfica de Ribeirão São lourenço en ITUIUTABA/MG

Resumen - La degradación de suelo puede ser evitada a partir de estudios que indiquen el potencial del uso de la tierra. El objetivo de este trabajo fue evaluar la capacidad del uso de la tierra y reconocer las áreas prioritarias para su preservación en la cuenca hidrográfica de Ribeirão São Lourenço en Ituiutaba/MG. A través de técnicas de geoprocesamiento los datos fueron compilados para la clasificación de tierras en el sistema de capacidad de uso. Aproximadamente el 88,82\% del área de la cuenca está apta para la agricultura (clases I y II). En la clase IV el uso agrícola es más restringido, siendo indicado el cultivo perenne. Las áreas no aptas para el desarrollo de la actividad agrícola (clases VII y VIII) poseen potencial prioritario para la preservación, debido a las condiciones del suelo y su declividad. La clasificación de tierras aporta subsidios importantes en los procesos de planificación ambiental, indicando los usos posibles según su potencial, evitando la sub o sobreutilización de la tierra.

Palabras clave: Sistema de Información Geográfica, aptitud agrícola, capacidad de uso de la tierra, planificación ambiental.

\section{Evaluation Of LAND uSE CAPacity in Ribeirão São Lourenço’s watershed - ItUiutaba / MG}

Aвstract - The soil's degradation can be avoided from studies that indicate the potential of land use. This study aimed to evaluate the land use capacity and to recognize the priority areas for preservation in Ribeirão São Lourenço's watershed in Ituiutaba / MG. Geoprocessing techniques compiled the data to classify lands in the use capacity system. About $88.82 \%$ of the watershed's area is apt for agriculture (classes II and III). In class IV the agricultural use is more restricted, being indicated the perennial culture. The areas unfit for agriculture (classes VII and VIII) have priority potential for preservation due to 
soil conditions and declivity. The lands classification provides important subsidies in environmental planning processes, indicating the uses within their potential, avoiding under or over-utilization of land.

KEYwORDs: Geographic Information System, agricultural suitability, land use capacity, environmental planning.

\section{INTRODUÇÃO}

O uso da terra pode modificar a dinâmica e o funcionamento dos ecossistemas à medida que a vegetação é suprimida para dar lugar à agricultura, pecuária, construções urbanas etc. Tais ações podem desestabilizar o solo tornando-o vulnerável a processos erosivos, além de dificultar a permeabilidade da água no solo. Os danos podem ser evitados a partir de estudos que indiquem os melhores usos para determinadas áreas, considerando o potencial das terras.

Dentro deste contexto surge a necessidade de classificação das terras a fim de reunir características e propriedades semelhantes para adoção de usos e manejos mais adequados a cada região. Dentre os tipos de classificação de terras existe o sistema de capacidade de uso da terra que, segundo Lepsch et al. (2015 p. 67), constitui uma classificação técnica que visa "obter grupamentos de terras similares, com o objetivo de caracterizar a sua máxima capacidade de uso para agricultura sem o risco de degradação do solo...”.

O estudo da capacidade de uso da terra mostra-se útil em processos de planejamento, pois indica o uso adequado da terra e suas limitações como apresentado nos estudos de Mendonça et al. (2005); Giboshi et al. (2006); Castro et al. (2010); Silveira et al. (2013); Campos et al. (2016).

A aptidão agrícola das terras pode ser verificada a partir de outras metodologias como utilizado por Soares et al. (2008); Höfig et al. (2015); Poelking et al. (2015); Vasconcelos e Martins Júnior (2015). Essas metodologias se assemelham por relacionarem o tipo de solo, a declividade e as formas do relevo e se distinguem por considerarem diferentes níveis de manejo e por adotarem diferentes fatores físicos e químicos do solo para as análises.

Como observado por Soares et al. (2008), as metodologias para avaliação da aptidão agrícola/capacidade de uso não levam em consideração outras questões ambientais, principalmente em relação à legislação ambiental, sugerindo a necessidade de adaptação dessas metodologias para que as atividades agrícolas ocorram com menor impacto ao meio ambiente.

O objetivo deste trabalho é avaliar a capacidade de uso das terras e reconhecer as áreas prioritárias para preservação na bacia do Ribeirão São Lourenço.

Para alcançar esse objetivo é importante aliar a esse trabalho o uso de geotecnologias que têm sido utilizadas para o acompanhamento da acelerada expansão agrícola e ocupação do território. Dentre essas geotecnologias destacam-se os Sistemas de Informações Geográficas (SIGs) que funcionam como importante ferramenta na avaliação da aptidão agrícola das terras. De acordo com Assad (1993 p.180), esta avaliação constitui uma etapa importante na "definição de práticas adequadas de manejo e conservação do solo e da água, já que os SIGs podem facilitar o trabalho de representação gráfica das classes e atualização de informações”. Além disso, segundo Miranda (2010), os SIGs possibilitam a análise de interações complexas entre variáveis ambientais e sociais e a criação de cenários que preveem mudanças de comportamento dessas variáveis.

\section{Material e Métodos}

A bacia hidrográfica do Ribeirão São Lourenço, está localizada nos municípios de Ituiutaba e Prata, situados na mesorregião do Triângulo Mineiro, Minas Gerais. E localiza-se na zona 22S entre as coordenadas UTM 662895 - $697786 \mathrm{mE}$ e 7881421 - $7903875 \mathrm{mN}$ (Figura 1). 
Figura 1 - Mapa de localização da bacia do Ribeirão São Lourenço.

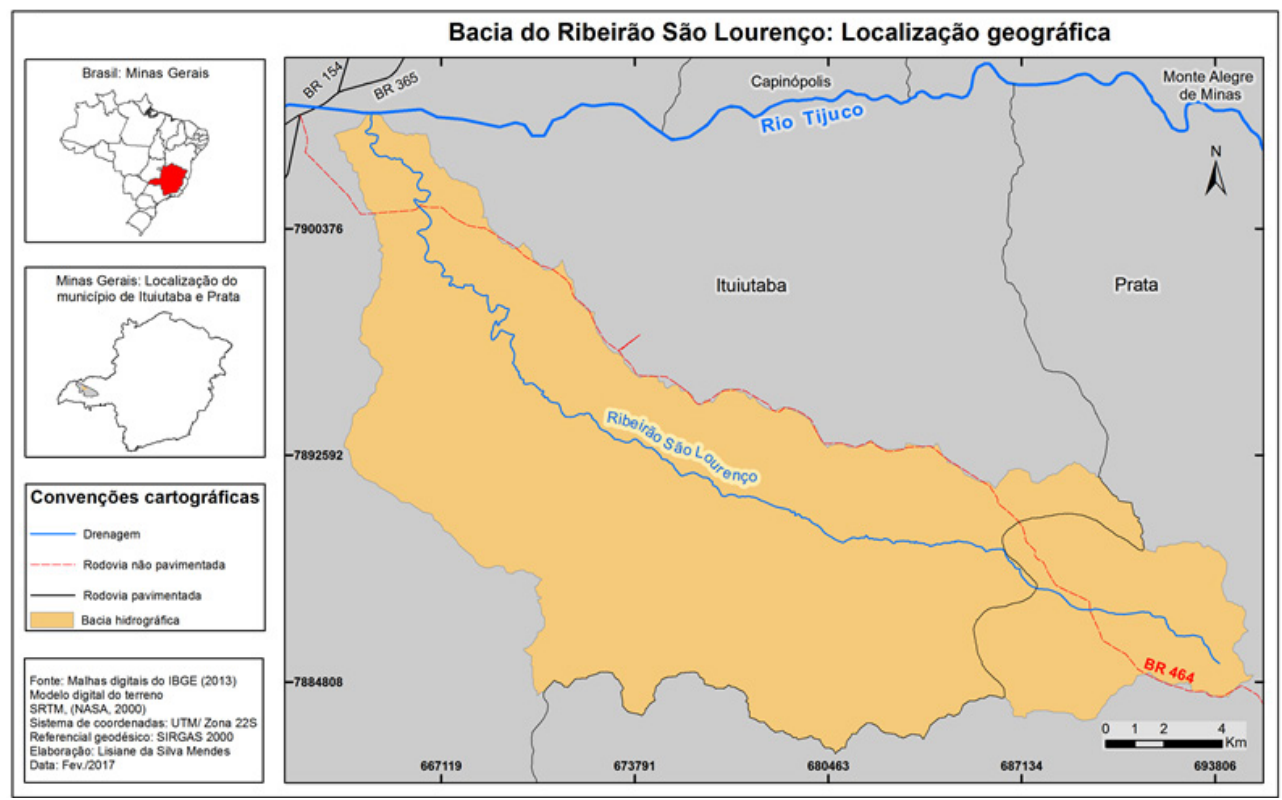

Fonte: Mendes (2016)

Para determinação da capacidade de uso das terras e das áreas prioritárias para preservação foi realizado, inicialmente, um levantamento do meio físico onde foram analisadas as variáveis: declividade e solo.

Com a utilização do Modelo Digital de Elevação/SRTM 30m disponibilizado pelo Serviço Geológico dos Estados Unidos - USGS foram elaborados os mapas declividade e solos. Os procedimentos foram realizados no ArGis 9.3.

As classes do mapa de declividade foram definidas de acordo com a classificação da Embrapa (1979), de forma a adaptá-la à proposta de Lepsh et al. (2015). Os valores de declividade superiores a 70\% foram pouco representativos na área de estudo, por isso a última classe criada obteve valores superiores a 45\% a fim de reunir as classes F e G propostas por Lepsh et al. (2015) (Quadro 1).

Quadro 1 - Classes de declividade adaptadas para utilização no trabalho.

\begin{tabular}{|c|c|c|c|c|}
\hline \multicolumn{2}{|c|}{ Lepsch } & \multicolumn{2}{|c|}{ Embrapa } & \multirow{2}{*}{$\begin{array}{c}\text { Classes Adaptadas } \\
<3 \%\end{array}$} \\
\hline A & $<2 \%$ & $<3 \%$ & Plano $(\mathrm{A}, \mathrm{B})$ & \\
\hline B & 2 a $5 \%$ & 3 a $8 \%$ & Suave ondulado $(\mathrm{B}, \mathrm{C})$ & 3 a $8 \%$ \\
\hline $\mathrm{C}$ & 5 a $10 \%$ & 8 a $20 \%$ & Ondulado $(\mathrm{C}, \mathrm{D})$ & 8 a $20 \%$ \\
\hline $\mathrm{D}$ & 10 a $15 \%$ & 20 a $45 \%$ & Forte ondulado (E) & 20 a $45 \%$ \\
\hline $\mathrm{E}$ & 15 a $45 \%$ & 45 a $75 \%$ & Montanhoso $(\mathrm{F})$ & $>45 \%$ \\
\hline $\mathrm{F}$ & 45 a $70 \%$ & \multirow{2}{*}{$>75 \%$} & \multirow{2}{*}{ Escarpado $(G)$} & \\
\hline G & $>70 \%$ & & & \\
\hline
\end{tabular}

Fonte: Adaptado de Lepsch (1991) e Embrapa (1979).

O mapeamento dos tipos de solos foi elaborado relacionando os mapas de geologia e declividade, a partir de uma adaptação da metodologia proposta por Oliveira (2012). O mapa geológico foi determinado a partir de trabalhos de campo, onde se observou a variação dos litotipos em áreas de afloramento ou em superfícies exumadas pelas drenagens fluviais. Assim, foram anotadas as cotas do ponto de contato entre o basalto do grupo São Bento (altitudes menores que $570 \mathrm{~m}$ ), arenitos finos da Formação Adamantina (altitudes maiores que $570 \mathrm{~m}$ ) e os conglomerados, fácies carbonosas e arenitos grossos da Formação Marília (altitudes maiores que 570 m), como apresentados no mapa de litoestratigrafia do Triângulo Mineiro de Batezelli (2003). 
A partir do reconhecimento geológico da área foi possível determinar os tipos de solo utilizando a metodologia descrita por Oliveira (2012), o qual verificou que a variação pedológica é condicionada pela distinção geológica e pelo relevo.

Para extração das classes de solo, primeiramente, foi necessário elaborar uma chave com alguns critérios estabelecidos no Quadro 2. Posteriormente, a partir da intersecção dos mapas de geologia e declividade, foram estabelecidos os tipos de solo.

Quadro 2. Chave de classificação dos solos.

\begin{tabular}{|c|c|c|}
\hline Geologia & Declividade (\%) & Solos \\
\hline \multirow{2}{*}{ Basalto } & $\leq 45 \%$ & Argissolo e Nitossolo \\
\cline { 2 - 3 } & $>45 \%$ & Cambissolo e Neossolo litólico \\
\hline \multirow{2}{*}{ Bauru } & $\geq 35 \%$ & Cambissolo e Neossolo litólico \\
\cline { 2 - 3 } & $<35 \%$ & Latossolo Vermelho \\
\hline
\end{tabular}

Fonte: Mendes (2016)

Pela pequena escala adotada nesta análise, ao invés de se definir classes de solo, optou-se por determinar associações de solos, caso contrário as classes seriam muito pontuais. Os solos hidromórficos encontrados na área foram obtidos a partir da vetorização de seus limites identificados por interpretação visual em tela das imagens dos satélites da Astrium disponibilizadas pelo Google Earth no software Qgis 2.8.3.

Para determinação da capacidade de uso da terra utilizou-se sistema de capacidade de uso proposto por Lepsch et al. (2015) que é organizado levando em consideração as seguintes categorias: classes, subclasses e unidades de capacidade de uso de terra. Tais categorias indicam a aptidão agrícola das terras assim como sua intensidade de uso de acordo com suas limitações.

As classes, representadas por algarismos romanos (I a VIII), são baseadas no grau de limitação de uso. As subclasses, identificadas por algarismos romanos e letras minúsculas (IIe, IIIe, IIIa e outras), são baseadas na natureza da limitação de uso. As unidades de capacidade de uso de terra fornecem informações mais específicas e detalhadas quanto à limitação do uso e são representadas a partir de algarismos arábicos dispostos depois da subclasse antecipados de um hífen (IIa-1, IIIc-2 e outras).

Para classificação da terra no sistema de capacidade de uso as características do meio físico são representadas por símbolos e notações dispostos em uma fórmula (1) (Lepsh et al. 2015). Nesta são informados os fatores determinantes do uso da terra como a profundidade (pr), textura $(\mathrm{t})$ e permeabilidade do solo (pm), além da declividade (d) e erosão (e). Também podem ser incluídos fatores limitantes e uso atual, sendo apresentados após a fração. Caso não haja fatores limitantes na área, estes podem ser omitidos da fórmula, a indicação do uso atual é utilizada em uma etapa posterior de recomendação à adequação de uso. A notação da fórmula não é matemática, apenas reúne as informações levantadas. Cada fator é representado pelo algarismo que indica seu grau de ocorrência.

\section{profundidade efetiva - textura - permeabilidade}

\section{declividade - erosão}

Fonte: Lepsh et al. (2015).

Após a obtenção das variáveis do meio físico optou-se por determinar a capacidade de uso das terras a partir do método sintético que considera as características de uma gleba como um todo (Alvarenga e Paula 2000; Lepsch et al. 2015). Assim, realizou-se a comparação dos fatores levantados em cada fórmula mínima, com a descrição de cada classe e subclasse de capacidade de uso da terra feita por Lepsch et al. (2015). Buscando, assim, encontrar a melhor classe e subclasse que representasse as características que compunham cada fórmula mínima. 
O mapa de capacidade de uso da terra foi obtido por meio do cruzamento do mapa de solos e do mapa de declividade, devido aos elementos da fórmula mínima que se referem principalmente aos solos e declividade. Assim como mostram outros estudos de avaliação da aptidão agrícola das terras Campos et al. (2010); Castro et al. (2010); Silveira et al. (2015); Campos et al. (2016).

Antes do cruzamento, o mapa de declividade passou pelo processo de filtragem para que houvesse uma suavização das classes. Deste modo, foi utilizado um filtro passa-baixa do tipo moda. Tal procedimento foi realizado no software Idrisi.

O levantamento das características do solo foi viabilizado a partir da literatura, visto que, levantamentos pedológicos detalhados ou semidetalhados são ausentes na área. As classes de profundidade, textura, e graus de permeabilidade encontradas no manual de Lepsch et al. (2015) tiveram os intervalos e a descrição comparados com os encontrados na Embrapa (2006), a fim de fazer a correspondência destas classes.

Neste trabalho não foram analisadas a erosão hídrica nem a laminar, apenas considerou-se para cada fórmula o potencial de erodibilidade de cada solo em relação à declividade/classes de solo como apresentado por Calderano Filho et al. (2014). Havendo assim uma associação de classes de declividade de Lepsch et al. (2015) para enquadramento no potencial de erodibilidade.

O mapa de áreas prioritárias para preservação foi obtido a partir do mapa de capacidade de uso da terra, pois as classes inaptas à agricultura correspondem às classes com potencial a preservação.

\section{Resultados e Discussão}

\section{Classes de capacidade de uso das terras}

Em relação à declividade cerca de $81,14 \%$ da área total da bacia tem relevo suave ondulado a ondulado. Nessas regiões os declives variam de 3 a $20 \%$, o uso de máquinas agrícolas torna-se mais limitante a partir de 10\% de declividade, devido à inclinação do terreno. Nessas regiões o potencial de erodibilidade é maior, salvo em regiões com solos muito permeáveis e pouco arenosos, como no caso dos Latossolos (Lepsch 1991).

Cerca de 88,23\% dos solos da área da bacia estão enquadrados na classe dos solos Latossolos Vermelhos, que possuem grande aptidão agrícola podendo ser utilizados para culturas anuais, perenes, pastagens e reflorestamento (Sousa e Lobato 2015). O seu alto potencial para agropecuária causa pressão em áreas que devem ser preservadas como APPs e reserva legal. No restante da bacia, 5,18\% correspondem à associação de Argissolo e Nitossolo, 4,32 \% representam os solos hidromórficos e 2,27\% pertencem ao Cambissolo e Neossolo Litólico.

A classificação da bacia no sistema de capacidade de uso ocorreu até o nível de subclasse, devido à falta de informações sobre as características físicas e químicas do solo que norteariam a determinação das unidades de capacidade de uso. Além disso, a escala de trabalho inviabiliza a indicação de manejos em uma propriedade rural. As fórmulas mínimas encontradas para cada tipo de solo são apresentadas no Quadro 3, que também mostra a variação da declividade e do potencial de erodibilidade. 
Quadro 3. Fórmula mínima determinada para cada tipo de solo da bacia do Ribeirão São Lourenço.

\begin{tabular}{|c|c|c|c|}
\hline \multirow[b]{2}{*}{ Tipo de solo } & \multirow[b]{2}{*}{ Fórmula mínima } & \multicolumn{2}{|c|}{ Variações } \\
\hline & & Declividade & Erosão \\
\hline Argissolo e Nitossolo & $\frac{2-2-1}{\text { Declividade - erosão }}$ & $\mathrm{AB}$ a $\mathrm{E}$ & Nulo a alto \\
\hline $\begin{array}{c}\text { Cambissolo e Neossolo } \\
\text { litólico }\end{array}$ & $\frac{4-3-1}{\text { Declividade - erosão }}$ & E e F & Alto a muito alto \\
\hline Latossolo vermelho & $\frac{1-3-1}{\text { Declividade - erosão }}$ & $\mathrm{AB}$ a $\mathrm{E}$ & Nulo a alto \\
\hline Solo hidromórfico & $\frac{3-1-3}{\text { Declividade - erosão }}$ & $\mathrm{AB}$ e $\mathrm{BC}$ & Nulo a muito baixo \\
\hline
\end{tabular}

Fonte: Mendes (2016).

Após as definições do sistema de capacidade de uso, foram encontradas cinco classes (Figura 2) e oito subclasses (natureza de limitação: potencial de erodibilidade, tipo de solo e excesso de água) segundo as determinações de Lepsch et al. (2015).

Figura 2. Mapa de capacidade de uso da terra.

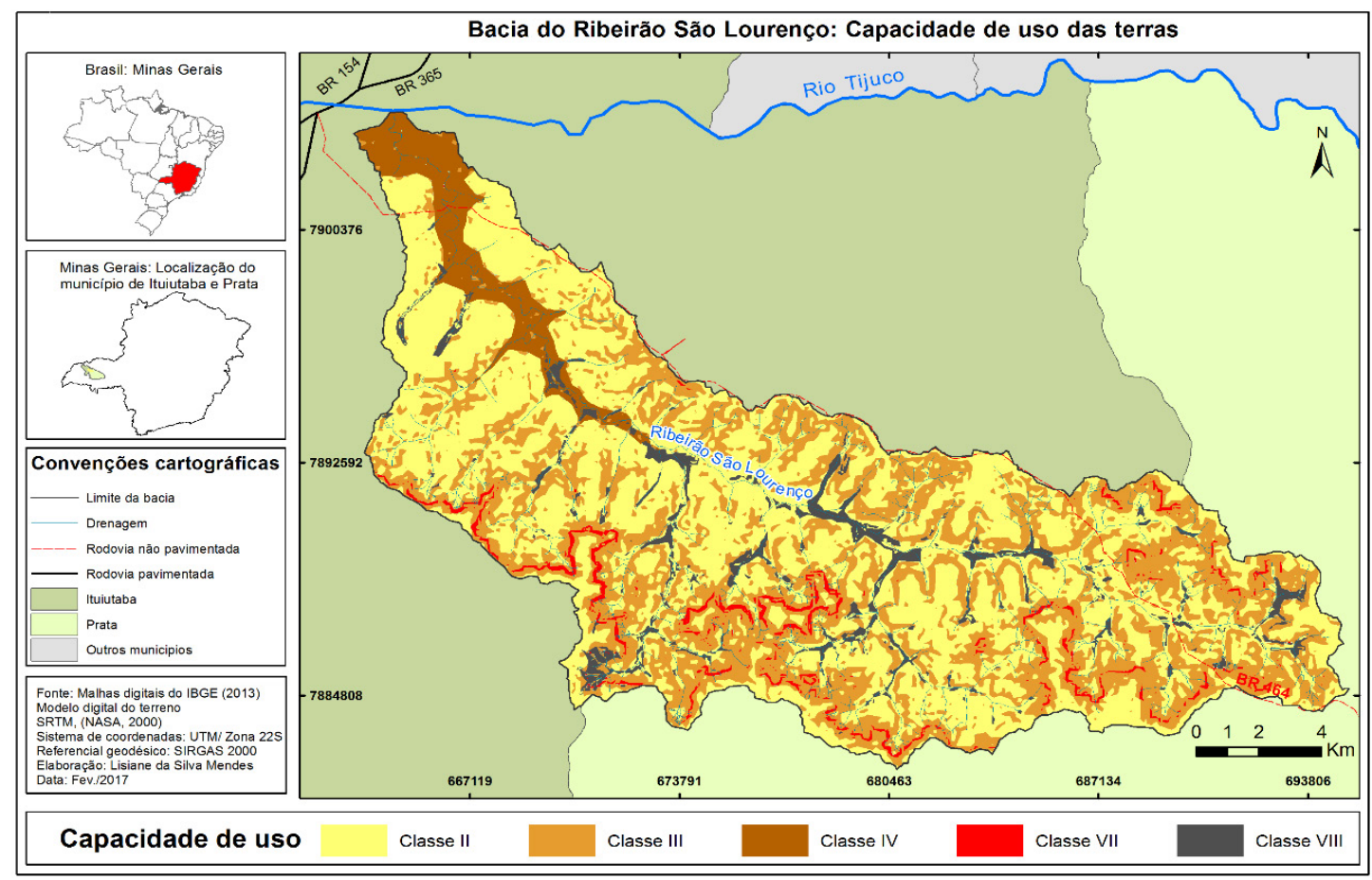

Fonte: Mendes (2016)

O mapa acima apresenta as classes de capacidade de uso onde é possível observar a predominância das classes II e III, as quais possuem maior aptidão agrícola (Tabela 1). Do mesmo modo é possível verificar que no limite da bacia estão as regiões com menos aptidão agrícola representadas pela classe VII, em vermelho, juntamente com a classe VIII, em cinza, localizada no interior da bacia. 
Tabela 1. Área das classes de capacidade de uso da terra na bacia do Ribeirão São Lourenço.

\begin{tabular}{ccc}
\hline Classes & Área (ha) & Área (\%) \\
\hline II & 15017,95 & 51,03 \\
III & 11121,89 & 37,79 \\
IV & 1445,97 & 4,91 \\
VII & 621,02 & 2,11 \\
VIII & 1223,27 & 4,16 \\
\hline TOTAL & $\mathbf{2 9 . 4 2 9 , 1 0}$ & $\mathbf{1 0 0 , 0 0}$ \\
\hline
\end{tabular}

Fonte: Mendes (2016).

As terras pertencentes à classe II são próprias para cultura necessitando de práticas simples de conservação, já aquelas da classe III são próprias para lavouras em geral, mas devem ser observadas as limitações e os cuidados devidos no caso de culturas anuais, pois quando manejadas dessa forma, correm risco de degradação (Lepsch et al. 2015). Sendo assim, em torno de $88,82 \%$ da área da bacia está apta à agricultura, no entanto, deve-se observar, nesse percentual, a existência de áreas de preservação permanente que correspondem a 12,64\% da área total da bacia (Mendes, 2016). Esta situação ocasiona uma pressão sobre essas áreas.

A classe II obteve a subclasse IIs, cuja natureza de limitação se refere ao tipo de solo que na área de estudo está representado pelos Latossolos Vermelhos em declividades inferiores a 3\%. Apesar desses solos serem produtivos, podem apresentar baixa retenção de água e nutrientes e saturação por alumínio. Na subclasses IIe-s a natureza de limitação está restrita ao tipo de solo e ao potencial de erodibilidade, já que estão presentes Latossolos Vermelhos em declividades 3 a $8 \%$. Neste caso, são recomendados o plantio e cultivo em nível e a rotação com culturas de raízes profundas (Lepsch et al. 2015).

A classe III foi subdividida em subclasse IIIe e IIIs, a primeira corresponde aos Latossolos Vermelhos em declividades 8 a 20\% e 20 a 45\%, a limitação do uso se refere ao maior potencial de erodibilidade e a dificuldade de utilização de máquinas agrícolas, devido a declividade acentuada. Na segunda subclasse (IIIs) está presente a associação Argissolo e Nitossolo em declividades inferiores a 8\% a limitação refere-se à baixa fertilidade desses solos (Lepsch et al. 2015).

Na classe IV, o uso agrícola é mais restrito devido às limitações mais severas, por isso, não são indicados cultivos intensivos e sim o cultivo perene, para que não haja muita mobilização do solo, essa classe representa 4,91\% da área da bacia. Em concordância com Silveira et al. (2015), quando a classe IV é submetida a culturas anuais faz-se necessário práticas que melhorem as condições físicas do solos como a rotação de cultura, incorporação de matéria orgânica (liberação de nutrientes e manutenção da umidade), aumento da profundidade efetiva a partir de técnicas de esclarificação e subsolagem e correções químicas do solo.

A classe IV apresentou a subclasse IVe cuja limitação está relacionada ao potencial de erodibilidade devido a declividade acentuada presente na associação de Argissolo e Nitossolo em declividades 8 a $20 \%$ e 20 a $45 \%$ (Lepsch et al. 2015).

A classe VII obteve a subclasse VIIe-s onde está presente a associação Cambissolo e Neossolo Litólico em declividades 20 a 45\% e acima de 45\%, assim, as limitações se referem ao tipo de solo (solos rasos) e ao aumento do potencial de erodibilidade. Por isso, não é indicado cultivos intensivos, somente pastagem e/ou reflorestamento (Lepsch et al. 2015).

A classe VIII apresentou a subclasse VIIIa onde estão presentes os solos hidromórficos em declividades inferiores a $8 \%$, assim, a limitação está relacionada a má drenagem do solo e, por isso, não são indicados para o cultivo e sim para proteção e abrigo da flora e fauna silvestres (Lepsch et al. 2015). A Tabela 2 demonstra a distribuição das classes de capacidade de uso das terras por unidade de solos e classes de declividades da bacia em estudo. 
Tabela 2. Distribuição das classes de capacidade de uso das terras, por unidade de solos e classes de declividades.

\begin{tabular}{ccccc}
\hline \multirow{2}{*}{ Declividade (\%) } & \multicolumn{4}{c}{ Unidades de solo } \\
\cline { 2 - 5 } & $\begin{array}{c}\text { Latossolo } \\
\text { vermelho }\end{array}$ & $\begin{array}{c}\text { Argissolo } \\
\text { Nitossolo }\end{array}$ & $\begin{array}{c}\text { Cambissolo } \\
\text { Neossolo litólico }\end{array}$ & Solos hidromórficos \\
\hline$<3$ & II & III & & VIII \\
3 a 8 & II & III & VIII \\
8 a 20 & III & IV & \\
20 a 45 & III & IV & VII & \\
$>45$ & & & VII & \\
\hline
\end{tabular}

Classes de capacidade de uso

Fonte: Mendes (2016).

Considerando que o sistema de capacidade de uso avalia o potencial agrícola de acordo com um manejo em nível tecnológico alto, a intensidade de uso em uma classe poderia aumentar levando em consideração o cultivo manual ou a utilização de animais. Salvo em situações como destacaram Costa et al. (2008), os fatores declividade e profundidade do solo limitam o uso intensivo da terra e não podem ser melhorados pelo homem, por outro lado, a fertilidade e a suscetibilidade à erosão podem ser modificadas.

Segundo Lepsch (1991), no sistema de capacidade de uso, o potencial agrícola é baseado em características permanentes da terra (declive, textura, profundidade efetiva do solo etc.) e por isso, a melhoria de algumas condições para níveis de cultivo mais intensos não são possíveis.

\section{Áreas prioritárias para preservação}

As áreas inaptas à agricultura representam $6,27 \%$ da área da bacia e foram enquadradas nas classes de capacidade de uso VII e VIII que representam as áreas prioritárias para preservação (Figura 3).

Figura 3. Mapa de áreas com potencial para preservação.

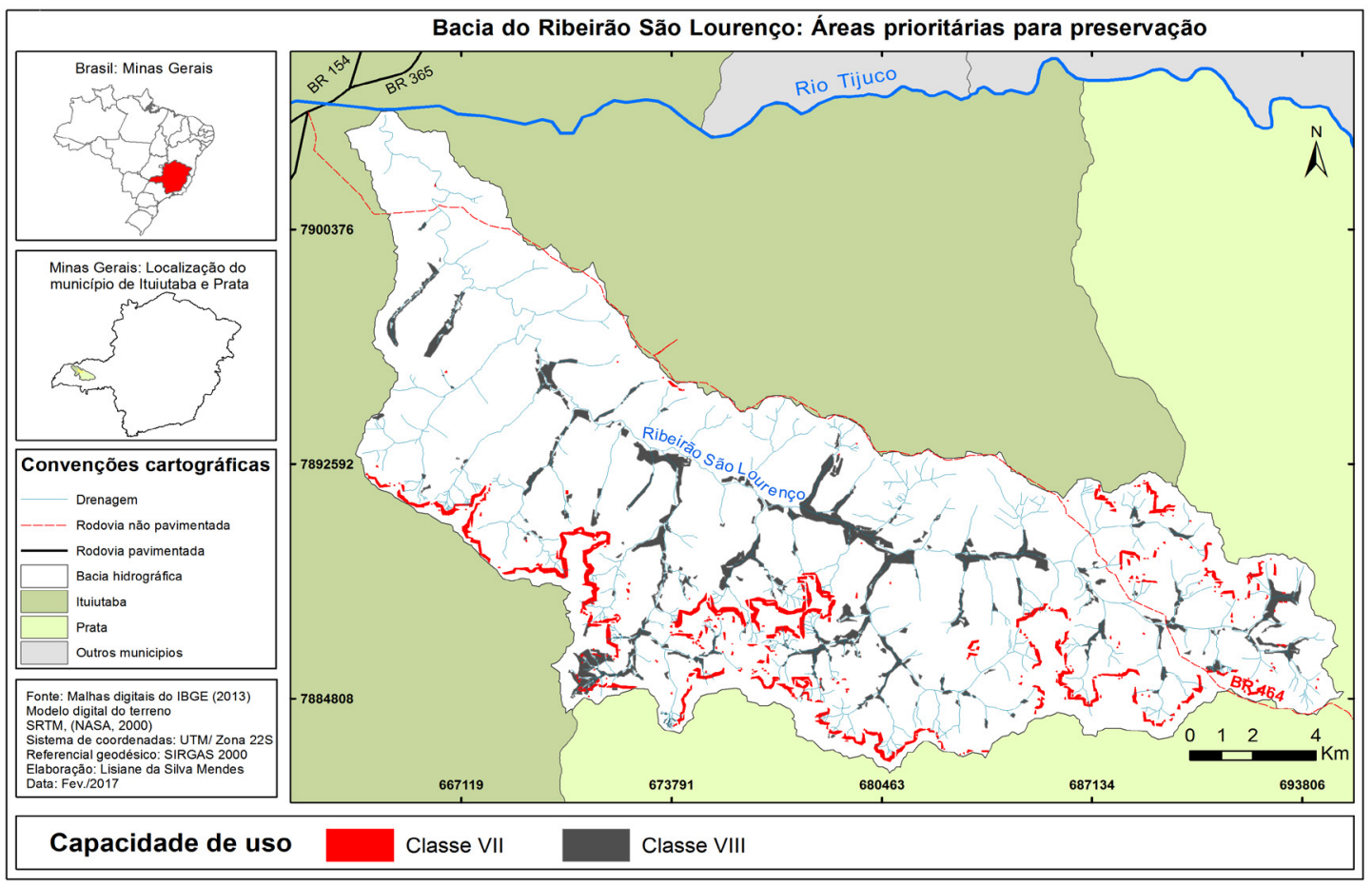

Fonte: Mendes (2016). 
Na classe VII existem várias limitações no uso para agricultura e oferece altos riscos de erosões devido às altas declividades. Em maiores declividades, ocorre o um aumento do volume e velocidade do escoamento superficial. O primeiro fator ocorre pelo fato de o solo não conseguir absorver uma grande quantidade de água em pouco tempo e sua velocidade aumenta pela ação da força da gravidade, com isso, os processos erosivos são intensificados. Os efeitos do escoamento superficial podem ser minimizados a partir da rugosidade do terreno, proporcionada por depressões e restos vegetais que diminuem a velocidade do escoamento superficial (Botelho e Silva 2004).

Na classe VII, o uso deve estar restrito à vegetação natural, salvo os usos de pastagem e reflorestamento com manejo adequado. Dessa forma, deve-se observar se há a aplicação de práticas conservacionistas na região da classe VII, visto que 11,32\% correspondem ao uso antrópico (pastagem, agricultura e silvicultura) e 88,68\% referem-se à vegetação natural (Tabela 3). Caso contrário, a região pode estar bastante suscetível a processos erosivos, mesmo dentro de sua capacidade de uso. A presença de agricultura nesta classe pode ser explicada pela adoção de um nível tecnológico menor ou até mesmo pela agricultura manual.

Tabela 3. Usos da terra na classe de capacidade de uso VII.

\begin{tabular}{ccc}
\hline Uso da terra & Área (ha) & \% \\
\hline Floresta & 273,17 & 43,99 \\
Cerrado denso & 54,21 & 8,73 \\
Cerrado ralo & 223,34 & 35,96 \\
Pastagem & 65,99 & 10,63 \\
Agricultura & 0,81 & 0,13 \\
Silvicultura & 3,49 & 0,56 \\
\hline TOTAL & $\mathbf{6 2 1 , 0 2}$ & $\mathbf{1 0 0 , 0 0}$ \\
\hline
\end{tabular}

Fonte: Mendes (2016)

A limitação quanto ao uso agrícola presente na classe VIII é devido à má drenagem do solo, nessas áreas são encontradas veredas onde devem ser observadas as restrições legais do uso da terra em seu entorno.

$\mathrm{Na}$ classe VIII estão presentes as áreas de veredas e campo limpo (no entorno das veredas), características de solos mal drenados, além disso, podem ser encontrados outros usos como apresentado na Tabela 4. Em torno de $3,68 \%$ desta classe não estão de acordo com a capacidade de uso por corresponderem aos usos antrópicos, pois a classe VIII deve ser destinada à preservação ambiental. De acordo com Lepsch et al. (2015), esta classe pode ser destinada à proteção e ao abrigo da fauna e da flora, para alguma utilidade turística, recreação ou armazenamento de água em represa.

Tabela 4. Usos da terra na classe de capacidade de uso VIII.

\begin{tabular}{crr}
\hline Uso da terra & Área (ha) & \multicolumn{1}{c}{$\%$} \\
\hline Floresta & 50,00 & 4,09 \\
Cerrado denso & 0,05 & 0,00 \\
Cerrado ralo & 0,23 & 0,02 \\
Campo/vereda & $1.129,21$ & 92,31 \\
Pastagem & 38,60 & 3,16 \\
Agricultura & 3,78 & 0,31 \\
Silvicultura & 0,10 & 0,01 \\
Represa & 1,29 & 0,11 \\
\hline TOTAL & $\mathbf{1 . 2 2 3 , 2 7}$ & $\mathbf{1 0 0 , 0 0}$ \\
\hline
\end{tabular}

Fonte: Mendes (2016). 
A região no entorno de veredas é considerada área de preservação permanente de acordo com a Lei 12651/12, Brasil (2012). A importância da preservação dessas áreas se deve ao fato de ocorrerem em locais de afloramento do lençol freático e, dessa forma, contribuírem para o surgimento de corpos d'água e a perenidade destes. Além disso, a vereda representa um local de refúgio, abrigo e alimentação da fauna e manutenção da flora (Boaventura 2007).

Tôsto et al. (2012) considerou que, para solucionar os problemas ambientais, seria necessário definir limites absolutos para o uso dos recursos naturais, ou seja, a determinar sua capacidade de suporte ou, ainda, de sua escala sustentável de produção agrícola quando se utiliza as terras dentro de sua capacidade de uso.

\section{Considerações FINAIS}

Aproximadamente $88 \%$ da área da bacia está apta para agricultura e pertence às classes II e III. No entanto, algumas técnicas de conservação devem ser realizadas para se evitar o depauperamento da terra. Além disso, devese observar nessas classes a existência de áreas de preservação permanente, para que sejam conservados os seus limites.

As áreas inaptas à agricultura representam $6,27 \%$ da área da bacia, esses locais têm alto risco de erosão ou má drenagem do solo, portanto, foram enquadradas nas classes de capacidade de uso VII e VIII. Os riscos de erosão estão ligados principalmente à declividade acentuada e ao tipo de solo naturalmente mais susceptível à erosão. A má drenagem do solo está relacionada aos tipos de solo hidromórficos, cujas características impedem o trabalho de máquinas agrícolas e o cultivo da maioria das culturas.

As atividades agrícolas devem ser realizadas respeitando a indicação da capacidade de uso das terras, observando suas limitações para evitar o esgotamento e degradação do solo. Visto que, quando observada a intensidade máxima de uso da terra, seu potencial produtivo se mantém, pois reconhece a capacidade de adaptação ao tipo de cultivo e manejo.

As técnicas de geoprocessamento utilizadas neste estudo possibilitaram a classificação, análise e cruzamento dos mapas temáticos para obtenção dos mapas de capacidade de uso e, também, a identificação das áreas prioritárias para preservação. Assim, geotecnologias como o sensoriamento remoto e o SIG mostram-se ferramentas importantes no estudo da capacidade de uso das terras.

Uma atualização da metodologia faz-se necessária principalmente acerca da questão ambiental, levando em consideração as áreas de APP. Assim, na metodologia do sistema de capacidade de uso, com a utilização do método sintético, poderia ser criada uma classe com as determinações das faixas de proteção das APPs segundo a Lei $12.651 / 12$.

\section{REFERÊNCIAS}

Alvarenga MIN, Paula MB. Planejamento conservacionista em microbacias. Informe Agropecuário, Belo Horizonte, v.21, n.207, p.55-64, nov. /dez. 2000.

Assad MLL. Sistema de Informações Geográficas na avaliação da aptidão agrícola de terras. In: Assad ED, Sano EE. ed. Sistema de informações geográficas: aplicações na agricultura. Planaltina: Embrapa, cap. 8, p. 171-96, 1993.

Batezelli A. Análise da sedimentação cretácea no Triângulo Mineiro e sua correlação com áreas adjacentes. Rio Claro, 2003. 195p. Tese (Doutorado em Geociências) - Instituto de Geociências e Ciências Exatas, Universidade Estadual Paulista. 
Boaventura RS. Veredas: caracterização. In: Vereda berço das águas. Tradução de Helena Mader. Belo Horizonte: Ecodiâmica, p. 33-81. 2007.

Botelho RGM, Silva AS. Bacia hidrográfica e qualidade ambiental. In: Vitte AC.; Guerra AJT.(Org.). Reflexões sobre a geografia física no Brasil. Rio de Janeiro: Bertrand Brasil, cap.6, p.153-189. 2004.

Brasil. Lei no 12.651 de 25 de maio de 2012. Dispõe sobre a proteção da vegetação nativa; altera as Leis nos 6.938 , de 31 de agosto de 1981, 9.393, de 19 de dezembro de 1996, e 11.428, de 22 de dezembro de 2006; revoga as Leis nos 4.771, de 15 de setembro de 1965, e 7.754, de 14 de abril de 1989, e a Medida Provisória no 2.166-67, de 24 de agosto de 2001; e dá outras providências. Diário oficial da união, Brasília, DF, 25 mai. 2012. Disponível em:<http://www.planalto.gov.br/ccivil_03/_ ato20112014/2012/lei/112651.htm>. Acesso em: 18 fev. 2017.

Calderano Filho B, Bering SB, Calderano SB, Guerra AJT. Suscetibilidade dos solos à erosão na microbacia do córrego Fonseca região serrana do estado do Rio de Janeiro. In: SIMPÓSIO REGIONAL DE GEOPROCESSAMENTO E SENSORIAMENTO REMOTO, 7., 2014, Aracaju. Anais... Aracaju: RESGEO, 2014, p. 571 - 576. Disponível em:<http://ainfo.cnptia.embrapa.br/ digital/bitstream/item/112789/1/Geonordeste'Trabalho-104-Braz-2-1.pdf >. Acesso em: 19 ago. 2015.

Campos S, Campos M, Nardini RC. Caracterização da capacidade de uso das terras de uma microbacia no interior paulista. Nativa, Sinop, v.4, n.5, p.328-332, Set- Out. 2016. Disponível em:<http://periodicoscientificos.ufmt.br/ojs/index.php/ nativa/article/view/3711>. Acesso em 18 fev.2017.

Campos S, Moreira KF, Pissarra TCT, Soares MC, Granato M, Mashiki MY, Ruggiero JKC. Geoprocessing apllied in the description of the classes of land use capability in the watershed of Alto Capivara, aiming its environmental sustainability. Pesquisa Aplicada \& Agrotecnologia. Guarapuava,v.3 n.3, p. 25-30, Set.- Dez. 2010. Disponível em:<http://revistas. unicentro.br/index.php/repaa/article/view/741>. Acesso em: 18 fev. 2017.

Castro LIS, Campos S, Zimback CRL. SIG - Spring aplicado na determinação da capacidade de uso das terras da microbacia do Ribeirão Pouso Alegre - Jaú (SP). Irriga, Botucatu, v. 15, n. 3, p. 268-274, Jul-Set. 2010. Disponível em:<http://irriga.fca. unesp.br/index.php/irriga/article/view/121>. Acesso em: 14 fev. 2017.

Costa GP, Souza JLM, Jesus MRG.Contraste entre duas metodologias de determinação do potencial agrícola das terras nas vilas rurais no município de Rio Negro, Estado do Paraná. Acta Scientiarum Agronomy. Maringá, v. 30, n.5, p. 687695, 2008.

Embrapa. Empresa brasileira de pesquisa agropecuária. Reunião Técnica de Levantamento de Solos, 10. Sûmu1a. Rio de Janeiro, SNLCS, 83 p. 1979.

Embrapa. Empresa brasileira de pesquisa agropecuária. Sistema brasileiro de classificação de solos. Rio de Janeiro: Embrapa Informação tecnológica, 306p. 2006.

Giboshi ML, Rodrigues LHA, Lombardi Neto F. Sistema de suporte à decisão para recomendação de uso e manejo da terra.

Revista Brasileira de Engenharia Agrícola e Ambiental, Campina Grande, v.10, n.4, p.861-866, 2006. Disponível em:< http://www.scielo.br/scielo.php?script=sci_arttext\&pid=S1415-43662006000400012 >. Acesso em: 18 fev. 2017.

Höfig P, Moura NSV, Giasson E. Aptidão agrícola das terras em Cerro Grande do Sul/RS. Boletim Gaúcho de Geografia. Por to Alegre, v. 42, n.1, p. 352-368, Jan. 2015. Disponível em:<http://seer.ufrgs.br/index.php/bgg/article/view/45132>. Acesso em: 14 fev. 2017.

Lepsch IF, (coord.) Bellinazzi JR, Bertolini D, Spindola CR. Manual para levantamento utilitário do meio físico e classificação de terras no sistema de capacidade de uso. Campinas: Sociedade Brasileira de Ciências do Solo, 1991. 175p. 
Lespch IF, Espindola CR, Filho OJV, Hernani LC, Siqueira DS. Manual para levantamento utilitário e classificação de terras no sistema de capacidade de uso. Campinas: Sociedade Brasileira de Ciência do Solo, 2015. 170p.

Mendes LS. Avaliação das áreas potenciais para preservação ambiental e áreas de conflito na bacia hidrográfica do ribeirão São Lourenço - Ituiutaba/MG. 2016. 76p. Dissertação (Mestrado em Meio Ambiente e Qualidade Ambiental) Instituto de Ciências Agrárias, Universidade Federal de Uberlândia, Uberlândia.

Mendonça IFC, Lombardi Neto F, Viégas RA. Classificação da capacidade de uso das terras da microbacia do Riacho Una, Sapé, PB. Revista Brasileira de Engenharia Agrícola e Ambiental, Campina Grande, v.10, n.4, p.888-895, 2006. Disponível em:<http:// www.scielo.br/scielo.php?script=sci_arttext\&pid=S1415-43662006000400016>. Acesso em: 18 fev. 2017.

Miranda JI. O que é um sistema de Informação Geográfica. In: Fundamentos de Sistemas de Informações Geográficas. Brasília: Embrapa Informação Tecnológica, cap. 1, p. 19 - 38, 2010.

Oliveira LA. Análise da qualidade de obtenção de classes de solos, no município de Uberlândia/MG, utilizando-se sistema de informação geográfica - SIG. Caminhos de geografia. Uberlândia, v. 13, n. 44, p. 113 - 127, Dez. 2012. Disponível em:<http://www.seer.ufu.br/index.php/caminhosdegeografia/article/view/16786>. Acesso em: 18 fev. 2017.

Poelking EL, Dalmolin RSD, Pedron FA, Fink JR. Sistema de Informação Geográfica aplicado ao levantamento de solos e aptidão agrícola das terras como subsídios para o planejamento ambiental do município de Itaara, RS. Revista Árvore. Viçosa, v.39, n.2, p.215-223, 2015. Disponível em: <http://www.scielo.br/scielo.php?pid=S0100-67622015000200215\&script=sci_ abstract\&tlng=pt>. Acesso em: 14 fev. 2017.

Silveira GRP, Campos S, Garcia YM, Silva HAS, Campos M, Nardini RC, Felipe AC. Geoprocessamento aplicado na determinação das subclasses de capacidade de uso do solo para o planejamento conservacionista. Comunicata Scientiae, Bom Jesus, v.4, n.4, p.330-336, 2013. Disponível em:<https://comunicatascientiae.com.br/comunicata/article/view/223>. Acesso em: 18 fev. 2017.

Silveira GRP, Campos S, Gonçalves AK, Barros ZX, Pollo RA. Geoprocessamento aplicado na espacialização da capacidade de uso do solo em uma área de importância agrícola. Energia na Agricultura, Botucatu, v. 30, n.4, p.363-371, Out-Dez. 2015. Disponível em:<http://revistas.fca.unesp.br/index.php/energia/article/view/1888/pdf_59>. Acesso em: 14 fev. 2017.

Soares MRGJ, Mellek JE, Orrutéa AG, Kummer L, Nunes T, Barros YJ, Andretta R, Favaretto N, Souza LCP. Potencial de uso agrícola e fragilidade ambiental da microbacia do rio campestre, Colombo - PR. Scientia Agraria. Curitiba, v. 9, n. 4, p. 587-596, Out. 2008. Disponível em: <http://ojs.c3sl.ufpr.br/ojs/index.php/agraria/article/view/13554/9176>. Acesso em: 14 fev. 2017.

Tôsto SG, Pereira LC, Romeiro AR, Mangabeira JAC. Espacialização da capacidade de uso das terras e escala sustentável para produção agrícola. Boletim da Sociedade Brasileira de Economia Ecológica. Rio de Janeiro, n. 29-31, p. 62 -66, Jan/Dez 2012. Disponível em: $<$ http://www.ecoeco.org.br/attachments/article/254/Book_Boletim_ECOECO_2931.pdf $>$. Acesso em: 09 fev. 2017.

Vasconcelos VV e Martins Junior PP. Information science and agricultural land suitability: interscalar approaches for land use planning. Revista Internacional Interdisciplinar INTERthesis. Florianópolis, v.12, n.2, p.221-245, Jul-Dez. 2015. Disponível em:<https://periodicos.ufsc.br/index.php/interthesis/article/view/1807-1384.2015v12n2p221>. Acesso em: 14 fev. 2017. 